\title{
Informal Education as a Derridean Gift: a Deconstructive Reading of the Principles Guiding Youth Work Practice Within Neoliberal Policy Regimes
}

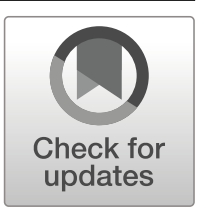

\author{
Ricky Gee ${ }^{1}$
}

Received: 23 April 2020 / Revised: 3 September 2020 / Accepted: 6 September 2020 /

Published online: 15 September 2020

(C) The Author(s) 2020

\begin{abstract}
This paper reflects upon the underpinning principles of informal education and youth work practice via the philosophical lens of post-structural philosopher Jacques Derrida, by introducing notions of the trace, différance, justice and the gift. Once these philosophical themes are introduced, they are then applied to the underpinning principles of informal education and youth work practice, as introduced by Jeffs and Smith $(1999,2005)$, paying particular attention to notions of voluntary participation, democracy, fairness, conversation and well-being. The paper asserts that such philosophical consideration of theory, and practice, can provide further insight into important dimensions of youth work, such as how it has been historically difficult to evaluate such practice in a policy domain, as well as pondering the tensions between its principles and pressures to 'professionalise' its service. The paper concludes by asserting the importance of informal education and youth work as a form of an improvised 'gift', one that is difficult to be subsumed within an overly administrative rational 'economy' so as to inform discussion and debate in theoretical, practice and policy domains. The paper argues that the use of a Derridean lens opens up such discussions via new considerations so as to assert the importance of youth work endeavours that challenge economic rationality.
\end{abstract}

Keywords Youth work · Youth policy $\cdot$ Philosophically informed practice $\cdot$ Derrida Différance $\cdot$ Trace $\cdot$ Gift

Ricky Gee

Ricky.gee@ntu.ac.uk

1 Department of Social Political Sciences, Nottingham Trent University, Room 3123, Chaucer Building, Nottingham NG1 5JQ, UK 


\section{Introduction}

Informal education and youth work are important factors that contribute toward the development of many young people transitioning toward adulthood in late modernity (Jeffs and Smith 2005; Hendersson et al. 2007; Davies 2010; Williamson 2007). Both youth work and informal education have a history that outlines its practical endeavours and its political consequences with a recursive relationship with theory and research. Jeffs and Smith $(1999,2005)$ are often considered to be important thinkers in the field of youth work and informal education providing core texts that inform the teaching and training of many youth workers. Taking this into account, much of youth work practice is guided by the principles of voluntary participation, democracy, fairness, conversation and well-being. The principles of conversation and voluntary participation account for how youth workers are to engage with the interests of the young people themselves and winning their consent rather than coercing their compliance (Williamson 2007). Taking such an approach moves youth work into the realm of a form of improvised practice which has no pre-set curriculum and no pre-set objectives (Jeffs and Smith 1999, 2005). Such a position is counter to many forms of policymaking within neoliberal regimes where the evaluation and impact of youth provision can be difficult to assert (Doherty and de St Croix 2019; Kloep et al. 2016). Jeffs and Smith have pondered on the difficulties that occur within rational econometric policy frameworks, which simplify endeavours, both retrospectively and projectively, whilst not taking into account the multiplicity and complexity of the 'reality' of practice, where money and profit, or efficient use of resources, are deemed to be of the highest order rather than the unfolding improvisation of practice and youth development. Such improvisation can therefore be counter to any rational order or pre-ordained formulae to guide the efficient use of resources for 'effective' practice that is likely to occur within policy domains. What is clearly of concern for Jeffs and Smith is the importance of qualitative evaluation so as to take into account the complexity of the work of informal educators, particularly when it is difficult to provide positivistic evidence of the cause and effect of informal education. Taking this into account, this paper wishes to inform such policy and practice considerations via the lens of French post-structural philosopher Jacque Derrida. Therefore, this paper has two major tasks: the first is to provide a brief summary of some of the thought of French post-structural philosopher Jacques Derrida, an important thinker of the late twentieth and early twenty-first centuries. The second task is to apply some of Derrida's concepts to important aspects of informal education, and in turn youth work, particularly those asserted by Jeffs and Smith $(1999,2005)$. The paper argues for the importance of informal education being viewed as a form of an improvised 'gift', one that is difficult to be subsumed within an overly administrative rational 'economy' so as to open discussion and debate in theoretical, practice and policy domains. The paper argues that the use of a Derridean lens challenges the technocratic and managerial economy at play in the evaluation of youth work practices, an invariably violent quantification of reality, where policy tends to challenge informal education principles of voluntary participation with no pre-set curriculum, so as to serve its funding masters. The paper argues that the use of a Derridean lens opens up such discussions via new considerations so as to assert the importance of youth work endeavours that challenge such economic rationality as well as providing a useful focus upon reflective practice (Gee and Barnard 2020). 


\section{Important Derridean Concepts}

Providing a summary of important Derridean concepts is not an easy task, as his thinking is notoriously difficult to access and understand, especially his infamous endeavour of 'deconstruction' (Royle 2008). To try and introduce a summary of Derrida is, in some respects, counter to the very notion of deconstruction, as a summary is to frame Derrida's ideas in a particular way, within a particular context, all of which needs to be considered and questioned when reading any interpretation of Derrida's, or any other thinker's, thought. In some respect, deconstruction has already started to occur, where one is to question the framing of a reading, even within the reading itself. However, before deconstruction runs away with its self and the paper appears to provide an overly apologetic caveat, it would be worth providing a contextualisation of Derrida's thought before its perceived application.

Jacques Derrida is considered by many to be a post-structural philosopher (Crotty 1998; Royle 2008; Sedgewick 2001), providing a challenge to structuralism, often considered to have been initiated by the anthropology of Levi-Strauss and via Saussure's structural linguistics in the early parts of the twentieth century. Structuralism puts forward the proposition that the foundations of human action relate to important elements of human culture, in terms of the relationship of cultural elements within a larger schema, an overarching system or structure. Structuralism therefore, as a mode of thought, is interested in revealing the 'structures' that lie beneath human action and texts - text in this case being anything that is deemed to provide textuality, for example, a written text, speech, images and sound such as songs. Structuralism, influenced by scientific discourse and thinking and a desire to discredit religion, which it perceived to be irrational and superstitious, works to uncover the structures that underlie all human action, therefore asserting a superior reading if one is to reveal the underlying law of universal structural relations (Crotty 1998; Royle 2008; Sedgewick 2001). Derrida asserts that structuralist accounts presuppose that which is fixed, which is stable, is an ontological norm and 'a defining feature of objectivity' (Sedgewick 2001, p. 197). Derrida (1982) argues that our understanding of the world comes from a sense of difference, that concepts and words only make sense by understanding what they 'are' in relation to what they 'are' also 'not'; therefore, when taking into account dual interrelating entities such as being and becoming, light and dark, night and day, male and female, Derrida is keen to acknowledge that structuralist's thought tends to incorporate a binary sense of hierarchisation, e.g. 'being' historically asserted as having more prominence than 'becoming' (Derrida 1982; Gray 2004). This further accounts for a privileging of literal language over metaphorical language. Derrida wishes to expose that the understanding of the so-called 'literal' is to take the form of metaphor via language and its interplay within unfolding structural relations, in a constant interplay of differing and deferring. For Derrida it is metaphorical 'play' that is so inherent in the production of meaning (Sedgewick 2001, p.206). The important notion here is that binaristic hierarchisation can provide an oppressive and limited lens upon our world view, which will shape our interpretation of the supposed universal structure of meaning that Levi-Strauss and Saussure wish to assert, something for which Derrida wishes to make apparent of structuralism. Derrida wishes to highlight the formation of the relationships between cultural elements, the so-called structural system, which is therefore never static and can be read in numerous and infinite ways. Therefore, the reading of such a structure, particularly where and when it places a sense of hierarchisation, is political and historical, where certain readings have the potential to benefit certain groups as opposed to others, e.g. male over female, which has historically been the case within 
western philosophy. Derrida wishes to assert the act of deconstruction to demonstrate the complexity and variability of reading the relationship of cultural elements. Deconstruction can therefore be viewed as an intent to think 'that' which cannot be thought due to already contradicting that which appears to be considered entwined yet also separate (Royle 2008), where meaning is not a matter that concerns only so-called 'literal' language, rather, "meaning is produced by a process of simultaneous differing and deferring" (Sedgewick 2001, p. 206) - Derrida's notion of différance (1982). Meaning therefore involves 'movement'-in this case 'between', 'within' and 'without' the already mentioned dual entities, e.g. male and female, day and night, that which never comes to rest as it depends on deferral. This may appear rather paradoxical to a reader unfamiliar to Derrida's work, yet this is an important aspect of Derrida's work - from the perspective of this paper. Inviting paradox asserts to question the relationship between supposedly related, yet often presented as separate, entities, i.e. how is male to relate to female and can the notion of male, or female, make any sense without the consideration of its supposed opposite; also how are we to consider other facets of gender that do not fall into such a neat and tidy dual framing, such as transgender? Deconstruction therefore is an intent to explore and challenge every day discourse and action, in particular by highlighting blind spots within everyday binary systems, e.g. being and becoming, male and female and light and dark (Derrida 1978). Deconstruction is a challenge to structuralist modes of thought, which Derrida holds to be characteristic of Western metaphysics (Sedgewick 2001; Derrida 1978, 1982, 1992). What Derrida wishes us to contemplate is how we frame our understanding of the world and how we may well unwittingly consider a bias toward certain modes of conceptual relationships, where historically we appreciate form over force and presence over absence. For Derrida such reflection upon any notion of bias is contextual and relates to the historical epoch and cultural framing of such action, where within the mode of western philosophy, from the preSocratics to Plato through to structuralism, there has been a preference of male over female, light over dark, being over becoming, form over force and presence over absence (Derrida 1982). For Derrida such consideration is to bring the notion of justice to the fore, where justice, for Derrida, is un-deconstructable, yet forever out of reach, a justice to come, a justice that is not 'law', as law is to be formulised and re-formularised. Therefore Derrida's thought is 'mad about justice' (Derrida 1992) as the activity of deconstruction embraces a form of 'self-criticism' that moves toward a critique of the metaphysics of presence, so as to challenge the priority and hierarchisation of everyday binary concepts (Peim and Flint 2013; Royle 2008; Crotty 1998).

Derrida's thought therefore questions the very nature of the metanarratives that have historically provided a sense of our own lives and daily actions. To challenge metanarratives, for example, notions of 'progress', what Sociologist Gellner (1972) would describe as a 'secularised salvation', a metanarrative of 'utopian emancipation', that modernists, critical theorists and resistant postmodernists may seek for, as highlighted by Lyotard.

The grand narrative has lost its credibility, regardless of what mode of unification it uses, regardless of whether it is a speculative narrative or a narrative of emancipation. (Lyotard 1979, p. 37-8)

To summarise the thought of Derrida is to challenge notions of structuralism, to challenge the idea that there is 'one' universal structure to be found to provide the secret to existence, a secret that transcends all history. For Derrida deconstruction is an 
endless endeavour seeking a justice that is always to come (Derrida 1992; Caputo 2000). It is at this point that the paper wishes to take into account that which has been traced so far, so as to consider one of Derrida's other concepts, the notion of the 'gift'. To do this is to consider how notions of the gift relate with notions of 'economy'. To explore the gift, we are to consider its characteristics via a sense of duality - to be viewed here as a conceptualisation of 'reality' that provides a paradoxical relationship between opposing yet entwining entities (Gee 2017).

\section{Gift and Economy as a Duality}

A gift, in Derrida's view, when acknowledged is always annulled and tainted. When one is giving or receiving a gift, there is a sense that the gift must be repaid and that the receiver is somehow in debt to the giver. Even the giving of a 'thank you' is to try and assert that the articulated gratitude in some way pays semblance to the given gift. Also, if the gift is given as a means of gaining a return, this is by no means a gift, or if a gift is given so as to satisfy a sense of self-righteousness, again, the gift is made void and thus becomes economy, a sense of equal exchange (Derrida 1992).

The gift "calls" upon us for an expenditure without reserve, for a giving that wants no payback, for distribution with no expectation of retribution, reciprocity, or reappropriation. To give a gift requires that one then forgets, and asks the other to forget, absolutely, that a gift has been given, so that the gift, if there is one, would vanish without trace. (Derrida and Caputo 1996, p. 143)

With the 'gift' being made explicit, with the receiver and the giver making conscious the transaction of the 'gift', Derrida (1992) suggests that economy is evoked - a cycle encouraging the exchange of goods looking to fill the debt evoked by initial enactment — and thus the 'gift' is annulled. The concept of the 'gift' is to tend toward the breaking of such a cycle of economy, to provide a "moment of madness, to do something for once without or beyond reason, in a time without time, and to give without return" (Derrida and Caputo 1996 p. 144). Such conceptualisation of the gift bears the gift impossible, yet Derrida claims that this is what makes the 'gift' so compelling and 'desirable'. The allure of the breaking of the economic cycle allows an aspect or a chance of the impossible to enter our existence; it pulls and tugs at the gaps in our knowledge and experience letting us:

... be driven by, impelled by, set into motion by, impassioned by this impossible desire, this desire for the impossible gift, for the impossible. (ibid, p.145)

Such impossibility of the gift-that which never makes an appearance yet is so desired - is in tension with economy, that which is the 'domain of knowledge'. Thus, the gift allows conceptions of becoming, yet such startled impossibility has to be comprehended within our present sense of being, that which is already mapped out via 'economy', our 'knowledge domain', that which requires judgement following preset formulae and calculation. The impossible challenges our notions of rationality and evokes a sense to seek the impossibility of the 'desirable'. In short to enact a life fully immersed within 'being' - thus economy — would be to stagnate, to pin down and to 
archive via an overly synchronic paralysis; life becomes saturated by a historically established knowledge base (Gee 2017). Yet becoming — thus akin to a gift—would allow overload to the senses as though struck by the everlasting emotional state of startlement (see Love 2008). Therefore, ones' condition of enactment is the tension provided by such duality, the duality of being and becoming and gift and economy (Gee 2019). At this point in the paper, one may well consider how such a conceptualisation may relate to the endeavour of informal education and youth work. It is here that the paper is to bring into play important conceptual considerations of informal education informing youth work practice and to then consider how notions of the duality of the gift and economy may well be a useful lens upon youth work practice.

\section{Consideration of the Principles of Informal Education via the Thought of Derrida}

Jeffs and Smith in their 1999 publication consider informal education via notions of George Elliot's character Holt, where Holt, a preacher within public houses, is considered to be an informal educator.

Felix Holt, chatting over a pint of beer, is not what many expect. Yet this is a good example of informal education. (Jeffs and Smith 1999, p. 9)

Jeffs and Smith (1999) assert that informal education, which resonate with the actions of Holt, is concerned with fostering environments for learning - potentially including those places that are not explicitly ascribed for learning - learning that does not follow a pre-set curriculum, which is not clear in where it is heading, one committed to democracy, fairness and truth. The endeavour of informal education is to engage with its participants via the unpredictable art of conversation, an art that requires improvisation. As expressed by Jeffs and Smith, the principles and values ascribed are "difficult to define and are often argued about" (p. 81). It is here that Jeffs and Smith implicitly bring into play notions of the gift accounted for in the previous section, where informal educators are to be reflexive practitioners and are to consider how their actions relate to notions of injustice and justice, so that educators can be aware of or justify their actions. Yet as Jeffs and Smith account for this can be difficult in the field of informal education, a pursuit that wishes not to ascribe pre-set outcomes or curriculum. As they suggest:

Aims are not spelt out on a daily basis. Would anything be more likely to alienate those we work with than constantly proclaiming 'I am here to do good, you know', or informing those within ear shot that 'my mission is to help you'. Some things are left best unsaid... (Jeffs and Smith 1999, p.82)

Here Jeffs and Smith, via the lens of Derrida's philosophy, are proclaiming the importance of the interplay between presence and absence, as well as considering the notion that our actions are not to be presented as a gift when in fact they are seeking a pay back of selfrighteousness, reverting the gift toward economy. It is also of note that Jeffs and Smith consider, implicitly, notions of gift and economy when considering the well-being of its 
'learners', where informal educators are to consider how their actions may evoke an emotional economy with significant others in their learner's lives:

A worker for example, would not be expected to give the address of the local refuge to an abusive husband seeking his wife, because they know it might put her and others at risk... (Jeffs and Smith 1999, p. 83)

The gift, in this sense the given of efforts toward the well-being of learners, is not necessarily traced, yet there is an awareness that to provide the information that the abusive husband seeks is to have potential, undesirable consequences. It is here that Jeffs and Smith bring forth the notion of voluntary behaviour of the informal learner that those that wish to take part in informal learning do so via their own supposed volition, not due to being coerced or bribed to do so. Again via the lens of the duality of gift and economy, we have an insightful reading that voluntary participation comes with a knowledge that one is to engage via a sense of 'intrinsic motivation', not because of an economy of explicit rewards such as money. However, is there still an economy at play? Does voluntary participation require some sense of reward? Are informal educators to be 'listened to' or potential 'role models' as they provide some 'intrinsic' reward for the 'learner'? If not acknowledged, a 'gift'? Does the informal educator expect any return for participation? Their own 'intrinsic' reward to continue their endeavours, to right the wrongs of their community via their own intention? The answering of such question are difficult, if not impossible to answer. Notions of voluntary participation, an important principle of both informal education and youth work, provide a sense of openness, a flexibility to work from the position of the learner, to avoid indoctrination and an overt sense of economy, where the actions of the learners are to not explicitly succumb to the wishes of the educator, yet may still become economised if indoctrination is to occur via coercive practice. At the same time, the openness of informal education may appear daunting to many, particularly those coming from a macro rational policy domain, those that may wish to heavily guide practice and behaviour, with the particular contemporary consideration of the distribution of financial goods within a neoliberal economy (Harvey, 2007). It is here that the paper wishes to consider the policy domain of informal education and its dilemma and tension in relation to professionalisation, where the duality of the gift and economy are again to be considered.

\section{Evaluating Informal Education Informed via the Duality of Economy and Gift}

Evaluation, in its original Latin sense, meant to strengthen. In recent years, evaluation has often come to mean something else. It has become a tool of funders wanting to judge what is 'successful', what 'works' and what should or should not be invested in. Rather than being an integral part of educating, this type of evaluation is more concerned with counting and comparing. (Jeffs and Smith 1999, p.72-73)

The above quote questions the notion of evaluation set within the realms of a rational econometric framework, one that simplifies endeavours, both retrospectively and projectively, and does not take into account the multiplicity and complexity of 'reality'. To fit 
within such a framework is to take heed toward the violent quantification of 'reality', where money and profit, or efficient use of resources, are deemed to be of the highest order. Such a rational order is therefore to present pre-ordained formulae to guide the efficient use of resources for 'effective' practice. Such consideration is undertaken by Jeffs and Smith whom indicate a three pronged approach to evaluation which involves 'direct evaluation', very fitting of the quote above, which is described as a means of managerial control; 'negotiated evaluation', a method of evaluation that is agreed by parties concerned and set in advance; and 'dialogical evaluation', which the educators and participants take responsibility for. What is clearly of concern for Jeffs and Smith is the importance of qualitative evaluation so as to take into account qualitative aspects of the work of informal educators, particularly when it is difficult to provide positivistic evidence of the cause and effect of informal education, as indicated below.

...change can rarely be monitored even on an individual basis. For example, informal educators who focus on alcohol abuse within a particular group can face an insurmountable problem if challenged to provide evidence of success. They will not be able to measure use levels prior to intervention, during contact or subsequent to the completion of their work. (Jeffs and Smith 1999, p.76)

Therefore that which is not traced, which cannot be measured, which provides no evaluative return, a return to be appreciated by the auditor's feedback to bodies with financial resources, is lost, not economised, yet may well have still provided a much useful 'gift'. It is here that informal educators find a tension between adhering to notions of professionalisation and the need to adhere to its principles of voluntary participation and delivery of learning from the learner's position via no pre-set curriculum. As indicated by Smith (2003, p.1), informal education via the endeavours of youth work has seen a push toward 'delivery', accreditation, individualisation and targeting and to a way of working that is very close to conventional North American approaches to youth development. To ensure compliance, the framework feeds into Ofsted's Inspection Framework for Youth Work and the central monitoring of youth services through action plans and the like.

Here Smith acknowledges the technocratic and managerial economy at play, where policy is to challenge informal education principles of voluntary participation, a principle found in much Youth Work theory, with no pre-set curriculum, so as to serve its funding masters. Yet such a challenge to such principles is to potentially disengage the potential learners that informal education seeks to work with, learners that may well be sceptical of such an economy, or where the behaviour of learners may adapt toward a superficial performance to gain action and development plans so as to receive reward, be it an objective within a sentence order or welfare benefit. However, at the same time though, informal educators, such as youth workers, have to work within and respond to changing economic and social conditions, which has the potential to form different terminology and emphases in some of its core features of practice and potentially the incorporation of new ones (Davies 2010); a profession that may well have to adapt in a manner to assert its impact, to provide an economic trace, to appease investors, to overtly professionalise, to assert "... strategies and rhetoric employed by members of an occupation in seeking to improve, status, salary and conditions" (Hoyle 1975, p. 315). Therefore, one is to question if such professionalisation, via Hoyle's critical lens, is to be of the sole benefit of the profession, funders, the community or a combination 
of? Yet such rational endeavour is to again provide an overt sense of economy, to not necessarily view the particular uniqueness of informal education, its ability to improvise and provide an untraced 'gift' of learning, one so counter to the array of practice in an overly marketised helping sector. As well as taking into account the difficulty of placing the act of 'helping' or facilitating informal learning against a monetary value, the reflexive practitioner may well wish to consider the duality of gift and economy in terms of their intended enactment (Gee and Barnard 2020). Does one engage with other for the benefit of the self? Or to benefit the other to again benefit the self? Deconstruction therefore provides useful questions to inform practice, from both macro and micro perspectives, to consider the array of 'economies' that are at play as well as what is presented as a 'gift'.

\section{Conclusion}

Youth work, like many public services, is caught within neoliberal policy and funding regimes, where the bottom line and efficiency of financial resources are of upmost importance. As mentioned previously, the arguments against such economic rationality are present within the literature (see Doherty and de St Croix 2019; Kloep et al. 2016) and theoretical principles of youth work, guided by informal education (Jeffs and Smith 1999, 2005), note well, the difficulties of youth work practice and make a case for its effectiveness beyond the bottom line. However, it is argued here that the duality of gift and economy, informed via Derridean philosophy, provides sharper focus upon such parameters, to celebrate the unique, improvised and collaborative art of youth work, yet also being mindful that such an art can be subsumed within marketised as well as emotional economies.

The thought of Derrida can thus inform reflexive endeavour, where the duality of gift and economy would be a useful inclusion in the pedagogy of youth work practitioners, not only to inform their work on the 'ground' but also to inform reporting 'up' to economic stake holders and policy makers, providing sharper articulation upon broader evaluative practice. Such a duality brings closer inspection upon macro policy framing, to question latent ideologies informing practice, where 'effective' practice asks what 'learning' is to be evoked, and whether learning is being coerced to placate, accommodate and/or domesticate its learners, possibly pulled by a desire to increase capital for and thus economising the profession. Moving practice toward the gift can bring the 'impossible' into play, a chance for novel or rejuvenated ways of working to be evoked, to benefit learners in ways not currently considered and to consider how this may be economised. Promoting the duality of gift and economy therefore enhances the reflexivity of actors to consider the inconclusive politics of the field, endeavour compelled toward the desire for justice, a justice that is always out of reach.

\section{Compliance with Ethical Standards}

Conflict of Interest The authors declare that they have no conflict of interest.

Open Access This article is licensed under a Creative Commons Attribution 4.0 International License, which permits use, sharing, adaptation, distribution and reproduction in any medium or format, as long as you give 
appropriate credit to the original author(s) and the source, provide a link to the Creative Commons licence, and indicate if changes were made. The images or other third party material in this article are included in the article's Creative Commons licence, unless indicated otherwise in a credit line to the material. If material is not included in the article's Creative Commons licence and your intended use is not permitted by statutory regulation or exceeds the permitted use, you will need to obtain permission directly from the copyright holder. To view a copy of this licence, visit http://creativecommons.org/licenses/by/4.0/.

\section{References}

Caputo J (2000) More radical hermeneutics; on not knowing who we are. Indiana University Press, Bloomington

Crotty M (1998) The foundations of social research. Allen \& Unwin, Crows Nest, Australia

Davies B (2010) What do we mean by youth work? In: Batslleer J and Davies B (eds.) What is youth work? Learning Matters, Exeter, pp 1-6

Derrida J (1978) Force and Signification. In: Derrida J (ed) Writing and difference. University of Chicago Press, Chicago, IL, pp 3-30

Derrida J (1982) Margins of philosophy. Harvester Press, Brighton

Derrida J (1992) Given time: I. counterfeit money. The University of Chicago Press, London

Derrida J, Caputo J (1996) Deconstruction in a nutshell; a conversation with Jacques Derrida. Fordham University Press, New York

Doherty L, de St Croix T (2019) The everyday and the remarkable: valuing and evaluating youth work. Youth and policy article at https:/www.youthandpolicy.org/articles/valuing-andevaluating-youth-work/ [accessed 1.4.20]

Gee R (2017) Contemplating 'career' across disciplines: reflexive explorations of 'career'. In: Barnard A (ed) Developing professional practice in health and social care. Routledge, London, pp 180-198

Gee R (2019) Exploring 'career' via the lens of paradox; a longitudinal study of the transitional experiences of a small group of graduates. Professional Doctorate Thesis, Document 5. Nottingham Trent University, Nottingham

Gee R, Barnard A (2020) Reflective practice via the lens of the life career and paradox: a contemplation of being and becoming a social worker. Reflective Pract 21:2, 210-221. https://doi.org/10.1080 $/ 14623943.2020 .1733953$

Gellner E (1972) Thought and change. Weidenfeld and Nicolson, London

Gray DE (2004) Doing research in the real world. Sage, London

Henderson S, Holland J, McGrellis S, Sharpe S, Thomson R, Grigoriou T (2007) Inventing adulthoods: a biographical approach to youth transitions. Sage, London

Hoyle E (1975) Professionality, professionalism and control in teaching. In: Houghton V et al (eds) Management in education: the management of organisations and individuals. Ward Lock Educational in association with Open University Press, London

Jeffs T, Smith MK (1997, 2005, 2011). 'What is informal education?', The encyclopaedia of informal education. [http://infed.org/mobi/what-is-informal-education/. Retrieved: [3.2.16]

Jeffs, T. and Smith, M.K (1999, 2005). Informal education; conversation, democracy and learning. Education New Publishing Co-operative Limited: Derbyshire

Kloep M, Hendry L, Taylor B, Stuart-Hamilton I (2016) Development from adolescence to early adulthood: a dynamic systemic approach to transitions and transformations. Psychology Pres, Hove

Love K (2008) Being startled: phenomenology at the edge of meaning. PhaenEx: revue de théorie et culture existentialistes et phénoménologiques; journal of existential and phenomenological theory and culture 3(2):149-178

Lyotard J-F (1979) The postmodern condition: a report on knowledge. University of Minnesota Press, Minneapolis

Peim N, Flint KJ (2013) Testing times: questions concerning assessment for school improvement. Educ Philos Theory 41(3):342-361

Royle N (2008) Jacques Derrida. Routledge, London

Sedgewick P (2001) Descartes to Derrida : an introduction to European philosophy. Blackwell, Oxford 
Smith MK (2003) 'From youth work to youth development. The new government framework for English youth services', Youth and Policy 79, Available in the informal education archives: http://www.infed. org/archives/jeffs_and_smith/smith_youth_work_to_youth_development.htm Retrieved: [3.2.16]

Williamson $\mathrm{H}$ (2007) Youth work and the changing policy environment for young people. In: Harrison R, Benjamin C, Curran S, Hunter R (eds) Leading work with young people. Sage, London 